\title{
METODOLOGÍA PARA LA NORMALIZACIÓN GRÁFICA DE LOS ESCUDOS DE REPRESENTACIÓN DIRECTA: EL CASO DEL ESCUDO NACIONAL DE ECUADOR
}

\author{
METHODOLOGY FOR GRAPHIC NORMALIZATION \\ OF DIRECT REPRESENTATION COATS OF ARMS: \\ THE CASE OF ECUADOR'S NATIONAL COAT OF ARMS
}

\author{
Rex Típton SOSA FREIRE \\ Universidad Central del Ecuador \\ rtsosa@uce.edu.ec
}

Resumen: El escudo ecuatoriano no es de armas porque no es heráldico, es de representación directa (viñeta). Pese a ser un símbolo nacional, no contaba con una metodología para su graficación y análisis. El estudio propuso el método DAERDI (Diseccionamiento analítico para escudos de representación directa) en atención a cinco ámbitos de estudio: forma y dimensiones, figuras, ornamentos externos, aspecto cromático y, como "un todo". Su aplicación permitirá estandarizar el diseño gráfico y la comprensión de sus contenidos. 
Palabra clave: Escudos. Viñeta. Representación directa. Método.

Abstract: The Ecuadorian escutcheon cannot be a coat of arms because it is not heraldic; it is an emblem of direct representation (vignette Shield). Despite being a national symbol, it has not had an appropriate methodology for its graphing and analysis. Thus, this study proposed the DAERDI Method (Analytical Dissection Method for Direct Representation Escutcheons Method), after deeming five respects: forms and dimensions, figures, external ornaments, chromatic features and as "a whole". Its application will allow standardizing the graphic design and the comprehension of its contents.

Key Words: Shield. Coat. Vignette. Direct representation. Method.

\section{INTRODUCCIÓN}

Más allá de proponer un método de graficación para la estandarización del escudo nacional ecuatoriano, el artículo se propone esclarecer los verdaderos alcances y significaciones que encarnan los escudos nacionales, especialmente los de representación directa mediante una nueva metodología de graficación. Esta será abordada desde cinco ámbitos de estudio que son: la forma y las dimensiones del escudo, las figuras que lo conforman, los ornamentos exteriores que lo adornan, la cromática de sus contenidos y ornamentos y como "un todo", es decir, como una unidad estructural de sentido. En general, los escudos de representación directa no son menos importantes que los típicos heráldicos, nada más, son diferentes y hay que concebirlos con todos sus atributos simbólicos. 


\subsection{Breve historia configurativa}

Ecuador y muchos otros países no tienen escudos de armas, puesto que, si bien es cierto provienen de la tradición europea, no disponen de piezas ni de figuras heráldicas. De la misma manera, tampoco se sujetan a la paleta de esmaltes conocidos por la ciencia del blasón y menos al concepto de simetría y proporcionalidad. Por lo tanto, el uso de la expresión de armas responde más a la tradición y no a otra condición. En su defensa, se puede argumentar que en algunos pasajes de su historia configurativa contó, y cuenta hoy, con armamento que se usó en las batallas de independencia (Sosa, 2014). Debido a esto, los tratadistas han optado por denominarlo de viñeta; sin embargo, en este trabajo se los va a llamar de representación directa, ya que su diseño cuenta con imágenes concretas con carácter representativo y/o simbólico.

\subsection{Propuesta de graficación}

En cuanto a la forma de graficar los escudos europeos, existen varios textos impresos de vieja data y en la actualidad, por ejemplo, el blog Dibujo heráldico de Xavier García (2011) que detalla los pasos a seguir para dibujarlos. Sin embargo, no existen estudios que expliquen la forma de graficarlos y menos de acceder a un entendimiento cabal de los escudos de representación directa

El presente trabajo se propone orientar un nuevo enfoque metodológico al que se lo ha denominado del diseccionamiento analítico para escudos de representación directa: DAERDI. Esta metodología se compara con la actividad médica con sus bases en la Anatomía, disciplina científica que tiene por objeto dar a conocer el número, estructura, situación y relaciones de las diferentes partes de los cuerpos orgánicos. De esta manera, se extrapolará la forma de estudiar la condición humana a 
la del símbolo, asumiéndose además que el escudo es un cuerpo completo y que para su comprensión global se lo estudiará primero por partes, en procura de conocer el número de sus componentes, sus significados, la estructura, su situación y sus relaciones intrínsecas. Solamente al final, se lo estudiará como "un todo" organizado y completo, tal y como se lo haría con el cuerpo humano. En definitiva, el trabajo permitirá elaborar un escudo razonado, graficándolo parte por parte y entendiéndolo en su verdadera dimensión simbólica.

Para su comprensión global, se recurrirá a los trabajos pioneros de Peter Burke para entender el valor que tienen y encarnan los símbolos y luego al método Panofsky, especializado en la descripción y análisis de obras pictóricas, pero acondicionado en este caso al estudio de los escudos de representación directa. En este aspecto, es importante aclarar que el método DAERDI, por su versatilidad, puede ser aplicado por un público no versado en la materia, así como también por académicos o estudiantes $\mathrm{y}$, de forma especial, por los diseñadores que trabajan la impresión de los escudos oficiales.

\section{CONSIDERACIONES PRELIMINARES}

A los escudos nacionales se los debe concebir como consecuencia de acuerdos sociales. Es necesario saber que, en calidad de símbolos, "no son ellos mismos el objeto o el concepto, sino que contienen su significado", Williams (1992:139). Es decir, detrás de aquello que perciben los sentidos se esconden innumerables contenidos ocultos. En los escudos de representación directa hay dibujos que representan ideas y conceptos, mientras que otros reflejan la realidad de los elementos naturales. Véase los trabajos de Claude Lévi-Strauss (1995), Roland Barthes (1994), A. J. Greimas (1973) que orientaron sus estudios en la comunicación no precisamente lingüísticos, sino a través de la imagen visual, la música, 
gastronomía, diseño, moda, fotografía, mitos, etc. (Bañuelos, 2006: 236).

$\mathrm{Su}$ valor se puede determinar según su grado de penetración en la mente de la población en términos de reconocimiento y memoria. Su relevancia como herramienta de comunicación y persuasión se evidenció en tiempos en los que la naciente república tenía un pueblo mayoritariamente analfabeto. De ahí la importancia de que gráficamente sea sencillo y de fácil reconocimiento y recordación. Un símbolo bien diseñado debe proporcionar acceso directo a una constelación de significados, enriquecidos por detalles que contribuyen al todo (Williams, 1992: 151). Súmese que además pueda ser copiado por cualquiera, es decir, que gracias a su sencillez sea fácil de leer y también de reproducir. En definitiva, tendrá significado solamente cuando sea comptendido por el grupo humano al que está dirigido y éste haya sido educado para reconocerlo y entenderlo y, al final, lo asuma como uno de sus símbolos representativos.

\section{METODOLOGÍA}

DAERDI es un método analítico sintético que permitirá diseñar y entender, parte por parte, sus componentes en proporción y relación de unos con otros, mediante cinco variables que serán estudiadas en el siguiente orden:

La primera, comprende las formas y dimensiones, tanto del escudo como de sus adornos externos. La segunda, sus contenidos internos, es decir, los objetos que constituyen el foco central del simbolismo, denominados figuras propias o heráldicas. Este aspecto se refiere a todas las piezas con que se carga y se adorna el escudo y que, según García (1920), se clasifican en cuatro grupos: propias o heráldicas, naturales, artificiales y quiméricas. Las figuras naturales serán las más socorridas en el presente estudio por ser las más recurrentes en el escudo ecuatoriano. Estas comprenden las siguientes: 
- Astros: Sol, Luna, estrellas, cometas, arcoíris, etc.

- Elementos: fuego, tierra, aire, agua

- Figuras humanas: ángeles, querubines, hombres, mujeres, ancianos, niños (unas veces representados con cuerpos enteros, otras, con bustos o partes del cuerpo)

- Animales cuadrúpedos: todos los animales están siempre mirando a la diestra y reflejando sus propiedades y naturaleza. Esto permite que las fieras se vean con mayor ferocidad, los domésticos en su mejor domesticidad y los estantes en su mayor estabilidad y firmeza.

- Aves: las domésticas cercanas al ser humano y las que desean estar lejos de él que, en general denotan libertad.

- Insectos y reptiles: se colocan volando o parados.

- Peces: puestos en palo, faja o banda.

- Plantas y minerales: árboles, plantas, flores y frutas.

La tercera variable tiene que ver con la descripción y análisis de los ornamentos exteriores. Todos aquellos que se disponen arriba, abajo y a los costados del campo. La cuarta, se refiere el aspecto cromático de sus elementos: unos cuentan con colores planos y otros son copiados a semejanza del entorno natural. Y, finalmente, la quinta, considera al escudo como un todo, es decir, al diseño se lo entiende como un cuerpo conformado por dos partes: la primera, el escudo o campo donde reposan todos los elementos que hablan de la nación; y, la segunda, sus adornos externos con base en la topografía del campo.

Es importante que se establezca una adecuada metodología de reproducción porque, como lo señala Umberto Eco al hablar del signo, 
"se utiliza para transmitir una información, para decir, o para indicar a alguien algo que otro conoce y quiere que lo conozcan los demás también" (Eco, 1988: 21). En este sentido, se debe establecer un adecuado proceso de comunicación mediante el siguiente orden: fuente - emisor - canal mensaje - destinatario:

- Fuente: El concurso convocado a inicios del XX.

- Emisor: El artista Pedro Pablo Traversari.

- Canal: La pintura en acuarela y soporte de cartón.

- Mensaje: La unidad nacional.

- Destinatario: La comunidad ecuatoriana.

De esta forma los signos, con la multiplicidad de connotaciones identificadas (Eco, 1995), se los puede asumir como componentes que señalan y son específicos de un cometido o una circunstancia (Williams, 1992: 139), en cambio los símbolos tienen significaciones más amplias y menos concretas. Aunque un solo signo, por si solo, puede constituirse en símbolo. Siguiendo a Williams, ambas son sutituciones y para que tengan significado se necesita que las comunidades las entiendan. Sin embargo, para entender un símbolo se requiere ir ligando, unos con otros, a la multiplicidad de sus componentes para encontrar, al final, el significado global de la misma manera que la sumatoria de palabras hacen una oración que tiene sentido.

\section{RESULTADOS}

\subsection{Forma y dimensiones}

A inicios del siglo XXI, la Cancillería ecuatoriana había descubierto 
que en el país circulaban alrededor de doscientas representaciones del escudo nacional, lo que determinaba que no había una unificación de su diseño ni una misma forma de representarlo ${ }^{1}$. Frente a esta contingencia, presentó una propuesta teórica-gráfica al Congreso de la República logrando que, en el año 2003, se expidiera la Resolución Legislativa N. ${ }^{\circ}$ R-24-047, por la cual se declaró su intangibilidad aprobándose además la redacción de un texto así como una representación gráfica. Sin embargo, este trabajo no reconoce tal representación por ser improcedente, sino la propuesta de Traversari, por su mejor organización estructural y porque, en 1916 fue dseclarado oficial del país.

¿Porqué su improcedencia? A continuación, se podrán distinguir las diferencias entre las dos propuestas gráficas e identificar las dimensiones y forma de sus óvalos / campos, punto crucial del diseño donde se acogen los conceptos fundamentales del mensaje que se quiso enviar a la población.
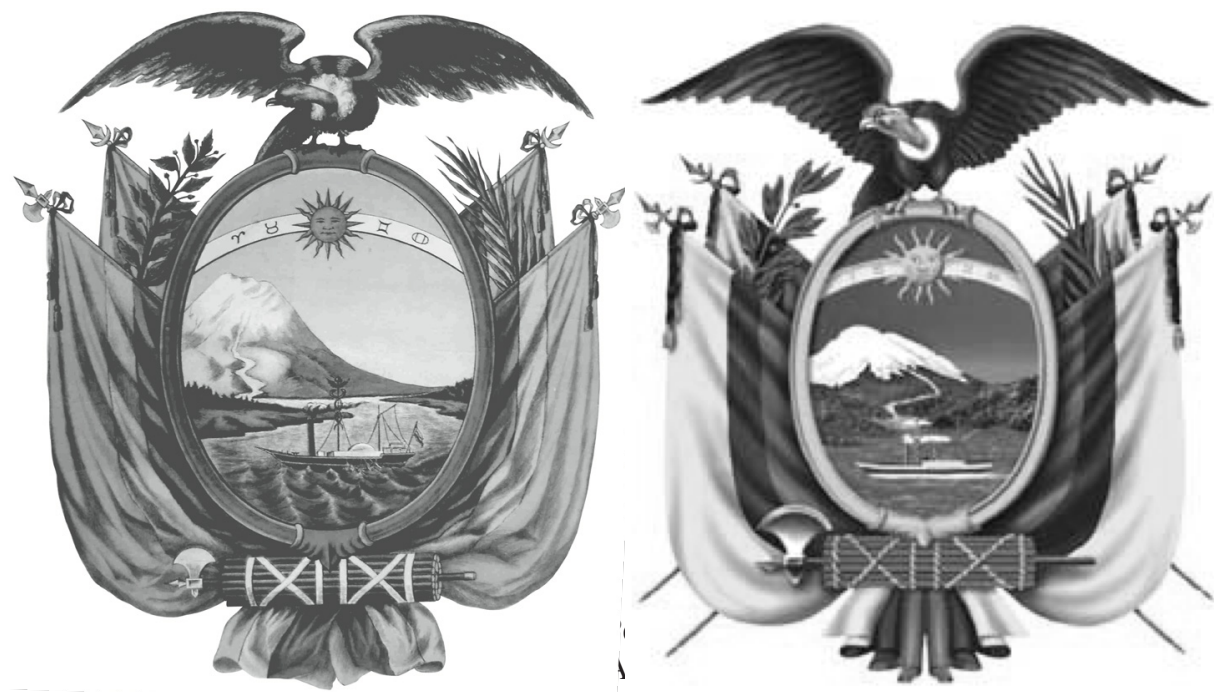

Fig. n. ${ }^{\circ}$ 2. Escudo propuesto por la Cancillería Ecuatoriana en el año 2003

${ }^{1}$ Intervención de la legisladora Guadalupe Larriva en el seno de Congreso Nacional, en el año 2003. 
Los óvalos difieren significativamente, pues el primero es más grande y prevalece respecto de sus ornamentos externos, no así el segundo que se halla empequeñecido. La mayor proporción del primero confiere mayor importancia y, el mensaje a transmitir es más notorio. Este hecho hizo que el modelo de Traversari triunfe en los albores del siglo XX, situación que no fue observada por quienes graficaron el modelo de la Cancillería, un siglo más tarde.

En tal virtud, este estudio diseccionará el diseño de Traversari, sin embargo, antes de proceder a tal cirugía, se identificarán primero los elementos que lo conforman, de esta forma, el lector los pueda identificar y ubicar, sin mayor dificultad, al momento de su intervención gráfica.

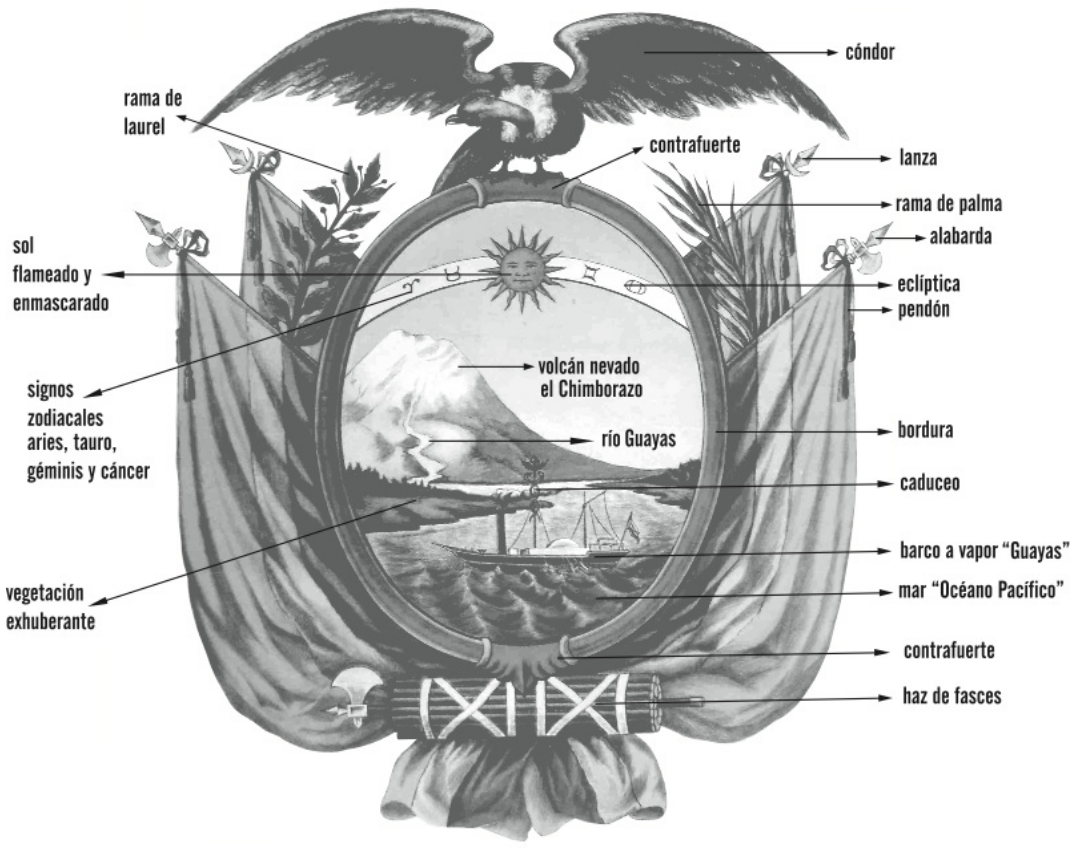

Hay que recalcar que la forma ovalada del campo utilizada por Traversari no corresponde a aquella que establece la geometría tradicional, sino a una figura diseñada ex profeso, mediante trazos de dibujo técnico, lo 
cual permite un mayor acopio de muebles. A continuación, se procederá a graficarlo siguiendo un patrón gráfico de base.

\subsubsection{La graficación del óvalo}

Según los tratadistas, el óvalo debía tener una proporción de 6 medidas de alto por 5 de ancho y esto tiene que ver con aspectos anatómicos, puesto que, en la antigüedad, el escudo se empleaba para proteger al guerrero o caballero en los combates y torneos, por tanto, debía cubrirlo en sentido vertical desde los ojos hasta el muslo o rodilla y, en sentido horizontal, proteger el pecho y los hombros. En consecuencia, para su graficación se requiere dibujar primero un rectángulo de 6 medidas de alto por 5 de ancho. Luego, al dividirlo con líneas verticales y horizontales, se obtendrán 30 cuadrantes que, para efectos de este trabajo, serán enumerados de izquierda a derecha y de arriba abajo, tal y como se lee la hoja de un libro. A este se lo llamará rectángulo base.

\begin{tabular}{c|c|c|c|c|c|} 
& & & & & \\
\hline 1 & 2 & 3 & 4 & 5 & \\
\hline 6 & 7 & 8 & 9 & 10 & \\
\hline 11 & 12 & 13 & 14 & 15 & \\
\hline 16 & 17 & 18 & 19 & 20 \\
\hline 21 & 22 & 23 & 24 & 25 \\
\hline 26 & 27 & 28 & 29 & 30 & \\
\hline & & & &
\end{tabular}

A continuación, se requieren dos círculos de 4,5 medidas de diámetro: uno superior y otro inferior. Para lograr el primero, se traza la línea horizontal A-B por la mitad de los cuadros 21, 22, 23, 24 y 25. Luego, se busca la parte central de la línea C-D que baja por la mitad de 
los cuadros $3,8,13,18$ y 23 .

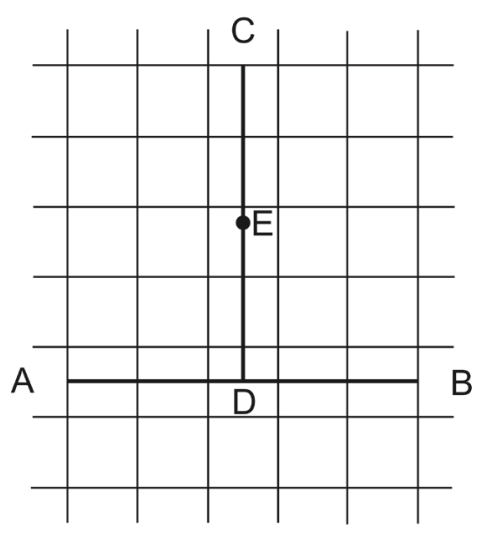

Partiendo del punto E, como eje, se traza un círculo cuyo diámetro pase por los puntos $\mathrm{C}$ y $\mathrm{D}$.

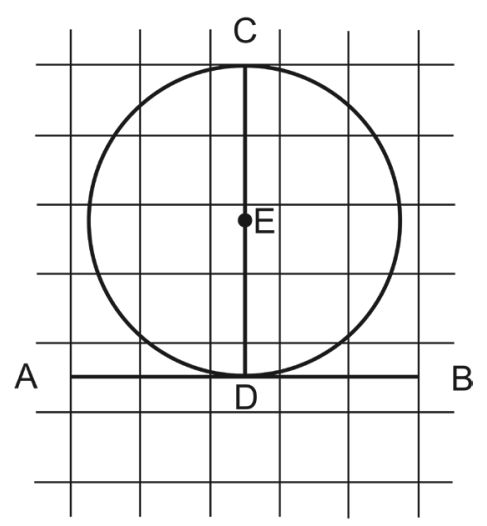

Se sigue igual procedimiento para trazar el segundo círculo en la parte inferior. 


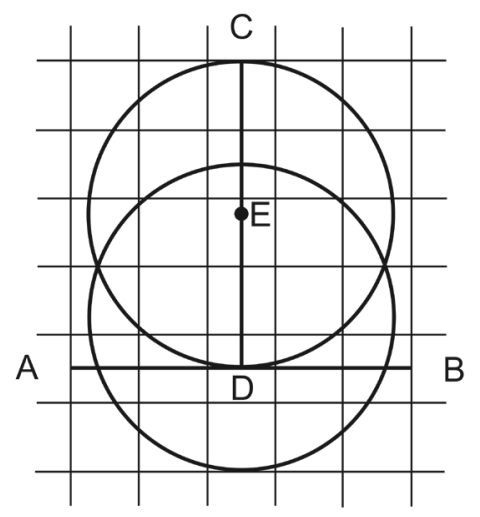

Después, el punto de intersección de los dos círculos sobre la línea central se toma como eje de uno nuevo, más pequeño, que pasa por la intersección del círculo superior con la tercera línea horizontal del rectángulo base y se encuentra un nuevo punto en la intersección de este círculo con la línea horizontal del centro (Paso 1).

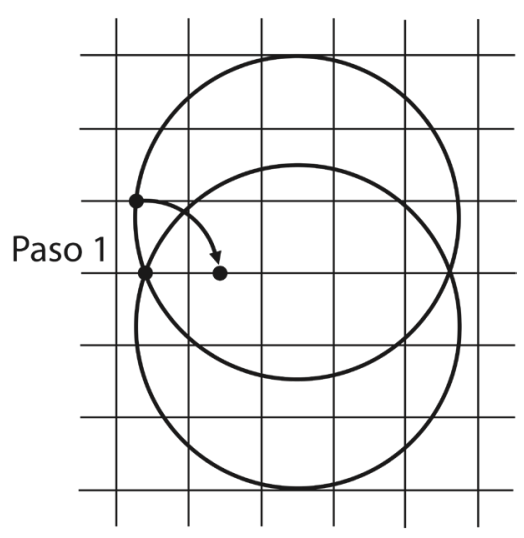

De este punto, se trazan semicírculos, al lado contrario, que unan las partes correspondientes de los hemicírculos superior e inferior (Paso 
2).

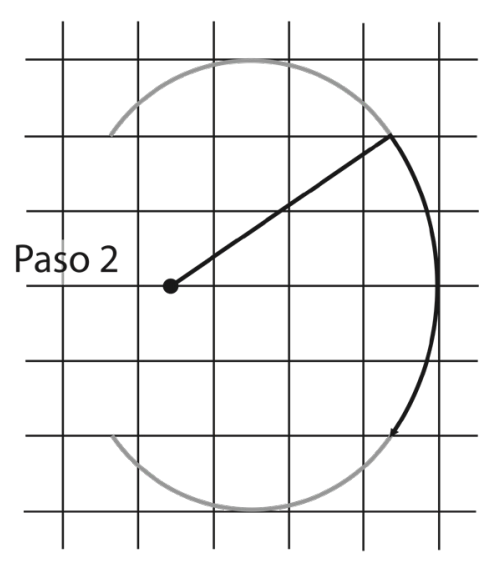

Luego, se sigue igual procedimiento en el lado contrario y se habrá completado el óvalo de Traversari.

\subsubsection{La bordura}

El escudo de Ecuador tiene como límite de su campo un ribete, cinta o faja. Según la terminología heráldica, esta pieza se denominaría bordura, por la posición extrema en que se sitúa, es decir, al borde del óvalo. Sin embargo, las borduras típicas tienen un ancho de $1 / 6$ respecto de la totalidad del campo, es decir, son mucho más anchas de la que presenta el escudo que apenas tiene 1/15. En virtud de este hecho, se la denominaría orla, aunque estas jamás están situadas en el límite externo, sino un poco por dentro, separados del borde, y tienen un ancho de 1/12. Por lo antes mencionado y a pesar de ello, se asume el término bordura por la posición que ocupa esta pieza, es decir que a partir del borde externo dibujado del ovalo se resta el espacio que ocuparía la bordura con una anchura de apenas $1 / 15$ partes respecto de la totalidad del campo. 
Para su graficación es menester subdividir los cuadros 3 y 28 del rectángulo base en cuatro partes. El óvalo mayor pasa por el punto más externo y el menor, de forma paralela, por la subdivisión interna.

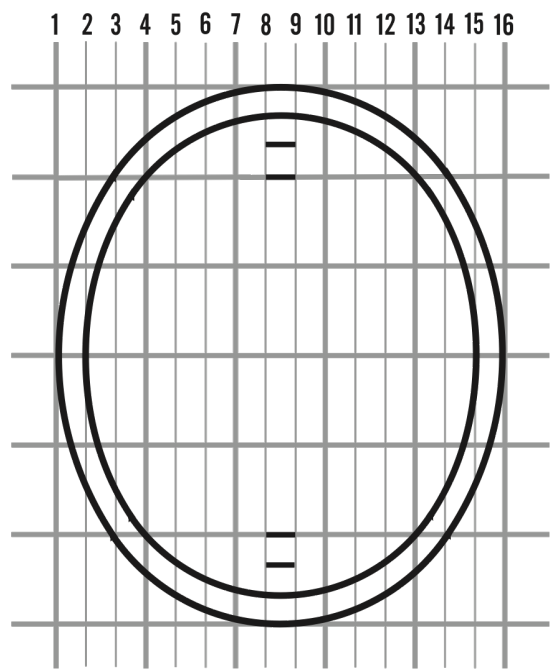

\subsubsection{Los contrafuertes}

En los textos de heráldica no se ha encontrado documento alguno que se refiera a su estructura y funcionalidad. Sin embargo, en el caso ecuatoriano, parecen reforzamientos de la bordura que sirven, el superior para soportar al cóndor $\mathrm{y}$, el inferior, a juzgar por la punta de ojiva en su parte baja, para encajar al escudo en el haz de fasces consulares. Tanto el uno como el otro le confieren una mejor configuración visual. 


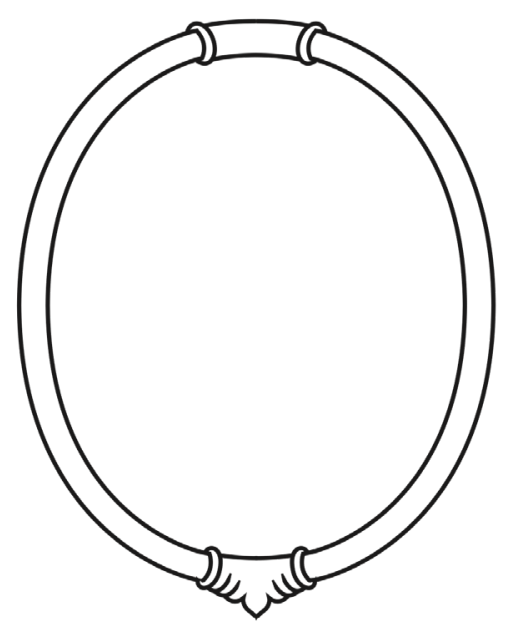

Estos dos elementos, que forman parte indivisible de la bordura, tienen una longitud de 1/5 respecto del ancho total del óvalo, es decir, lo que corresponde al ancho de un recuadro.

\subsubsection{El campo}

Se conoce por campo del escudo a la superficie que queda dentro de la bordura y en el que se identifican puntos de mayor o menor protagonismo. En tiempos antiguos, en estos puntos se colocaron los signos y señales de las noblezas, lo que permitió su diferenciación. En las viejas naciones, estos se formaron con las armas de los linajes de sus antiguos reinos. En cambio, en las sociedades modernas, estos corresponden a la flora, fauna, costumbres, tradiciones y otros elementos ajustados de cierta forma a las leyes heráldicas. En América, estos signos fueron reemplazados por elementos propios de cada país. 


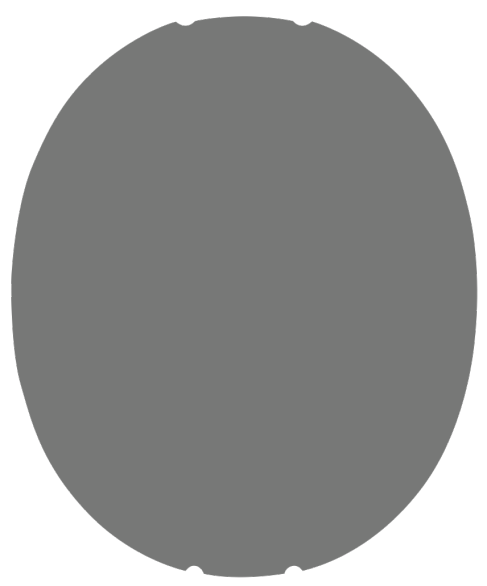

En este sentido, para efectos del lenguaje heráldico, los conceptos derecha e izquierda corresponden a diestra y siniestra del escudo. El jefe en su parte superior y la punta corresponde a la inferior. Los denominados flancos son los lados y/o costados, de ahí que tengamos flancos diestros y flancos siniestros. Las esquinas se llaman cantones. Así, en una correcta combinación de estos términos, tenemos la siguiente nomenclatura: cantón diestro y siniestro del jefe y cantones diestro y siniestro de la punta.

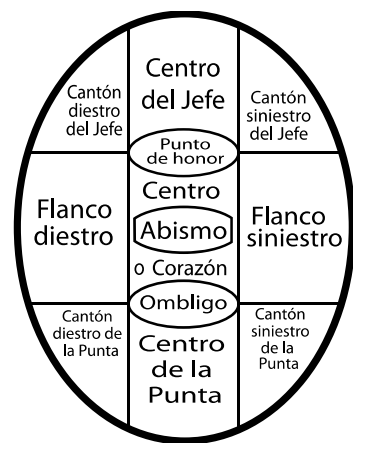

El campo cuenta además con una parte central que se dispone entre 
los flancos y de ahí que hallemos el centro del jefe en la parte superior y el centro de la punta en la inferior. Sin embargo, el propio centro se denomina abismo o corazón. Además, entre el centro del jefe y el centro o corazón se ha identificado un punto que se denomina punto de honor $y$, entre el centro o corazón y el centro de la punta, otro denominado ombligo.

Para realizar una descripción correcta, se procede como si se tratase de una persona vista de frente, su parte izquierda está a la derecha visual del observador.

Es importante señalar que bajo ningún concepto el campo del escudo debe quedar subsumido a planos secundarios respecto de sus adornos externos. En tal virtud, el observante debería fijar más su atención en su contenido interno y no en lo externo. Adviértase entonces, en el siguiente gráfico, que las proporciones de tales ornamentos no sobrepasan las dos medidas ni por arriba (el cóndor) ni por abajo (los extremos de las banderas y el haz de fasces consulares). En los costados, las banderas tienen una medida y media y serán solo las puntas de las astas las que alcanzan las dos medidas. En definitiva, los ornamentos externos laterales suman tres medidas respecto de las cinco del campo, en tanto, el superior como el inferior suman cuatro en relación con las seis medidas del campo.

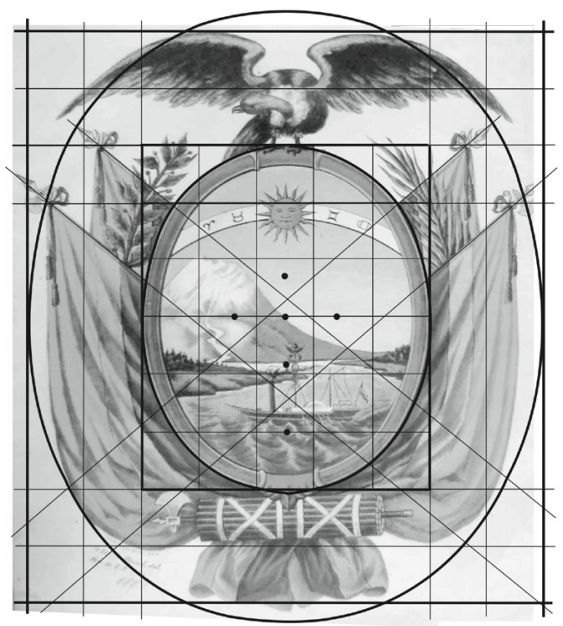




\subsection{Figuras del campo}

En los siguientes segmentos, se da inicio a la operación de cirugía interna de todos y cada uno de los elementos del campo, es decir, se ingresará a las entrañas de lo que, en el cuerpo humano, sería el tronco. Hay que tomar en cuenta que la norma heráldica determina que todos sus muebles, más aún si estos son animales, deben mirar y/o dirigirse a la diestra. En tal virtud, el Chimborazo, el volcán nevado más alto del Ecuador, está emplazado en el flanco diestro del que nace un río y el barco a vapor dirige su proa hacia la derecha. Solamente el caduceo y el Sol se encuentran alineados simétricamente en el centro del campo y estarían apegados a la norma heráldica.

En cuanto a los adornos externos, el cóndor mira en la misma dirección. Por otra parte, el laurel seguramente tuvo mayor importancia que la palma, de ahí su posición. Además, por si fuera poco, la punta de alabarda (hacha) del haz de fasces consulares también está dispuesta en esta dirección.

\section{La eclíptica y/o equinoccial}

Para su graficación, debemos encontrar el punto central de la línea que divide los recuadros 23 y 28 y trazar una curva que una las intersecciones del óvalo interior con la segunda línea horizontal del rectángulo base (Paso 1). Luego, desde el mismo punto inicial, se amplía el radio de la curvatura, se encuentra la segunda línea horizontal del rectángulo base y se traza la curva hacia la izquierda y derecha hasta encontrar la curvatura interna óvalo (Paso 2). 

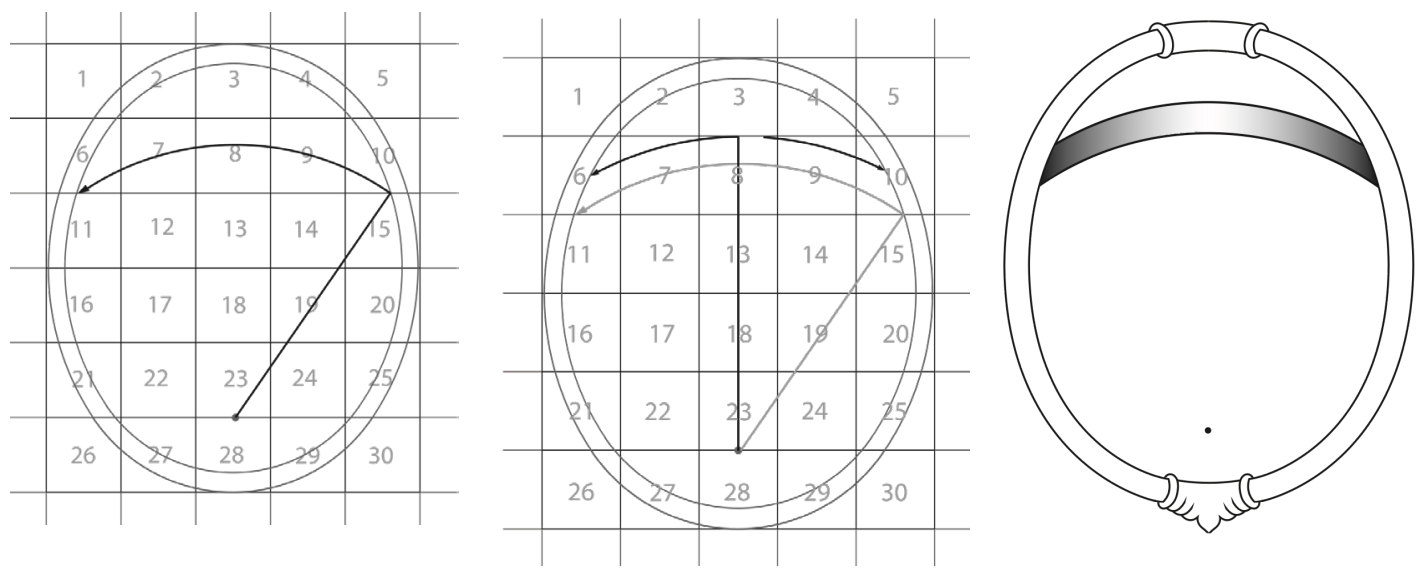

El Sol y los signos zodiacales

El Sol, incluyendo sus rayos, tiene más o menos la dimensión de un cuadro del rectángulo base. Se lo ubica en el centro de la eclíptica de manera que ocupe una parte del cuadro ${ }^{\circ}{ }^{\circ} 3$ y otra del n. ${ }^{\circ} 8$. Por su parte, los signos zodiacales, dos a cada lado. Aries y Tauro, se ubican a la derecha y dentro del cuadro n. ${ }^{\circ} 7$, mientras que Géminis y Cáncer se sitúan a la izquierda y dentro del cuadro $n .^{\circ} 9$.
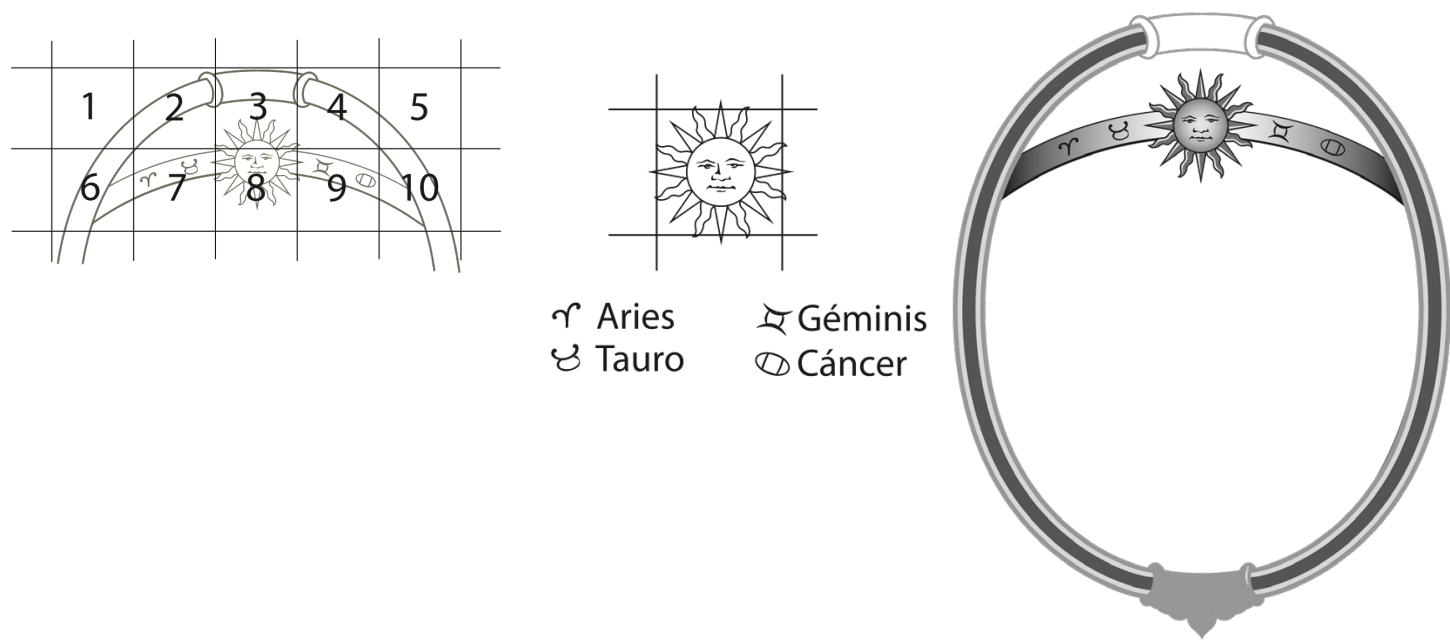


\section{El Chimborazo}

Visto desde Guayaquil, este volcán presenta tres picos en su cresta, ordenados desde el más alto, al extremo derecho, al más bajo, al centro del escudo. Su corona helada ocupa mayoritariamente los cuadros $n .^{\circ} 12$ y 13 , mientras que sus faldas se encuentran en los cuadros $\mathrm{n}^{\circ}{ }^{\circ} 16,17,18,19 \mathrm{y}$ 20. En general, toda la montaña se extiende sobre las franjas horizontales tercera y cuarta, dejando libres los cuadros 14 y 15.
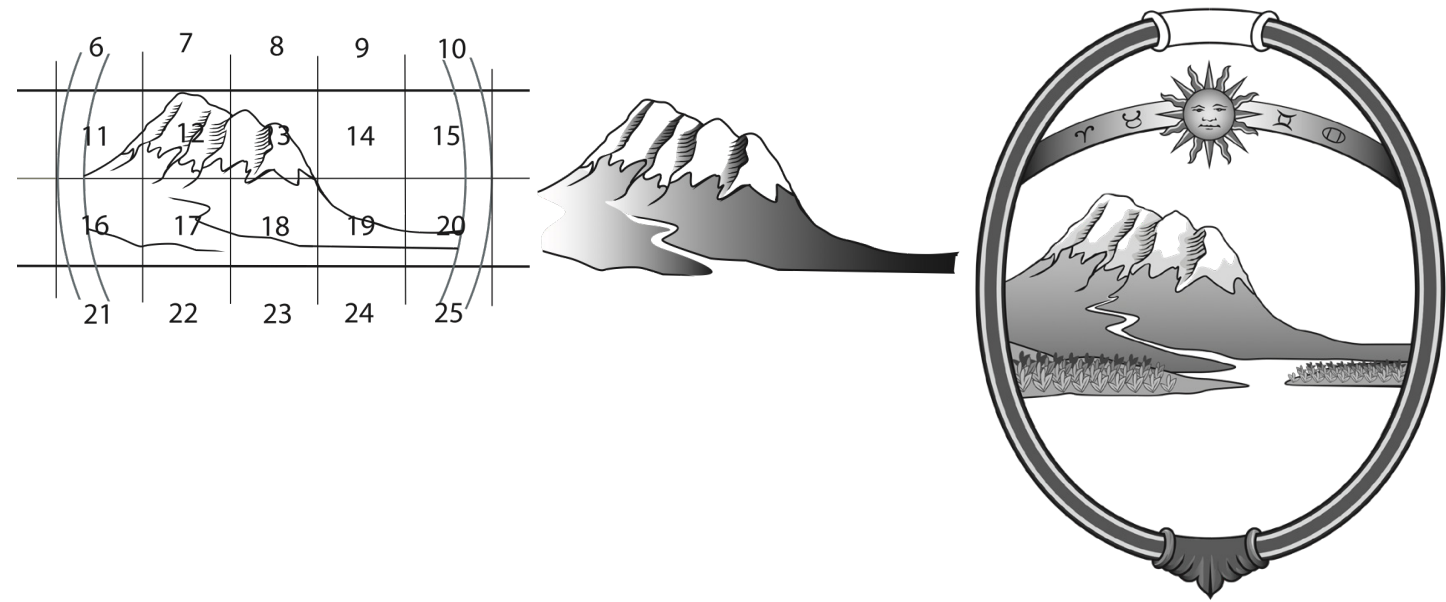

El río Guayas y el océano Pacífico

El río nace de los deshielos del Chimborazo y, conforme baja zigzagueante a la costa, la parte inferior del óvalo se ensancha hasta terminar en el oleaje del mar-océano. En sus inicios, ocupa la cuarta franja horizontal, mientras que su porción mayor se ubica en la quinta franja y el oleaje del mar, en la sexta. A orillas del río se expande una frondosa vegetación. 

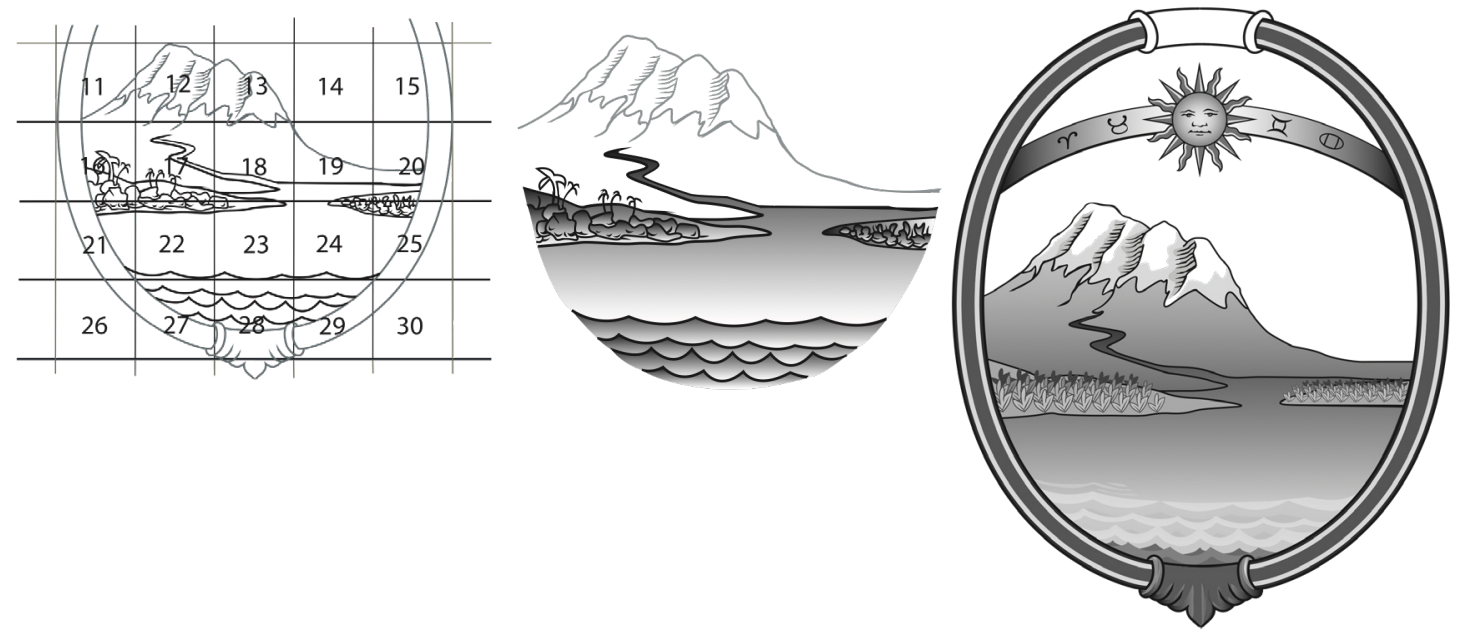

El barco a vapor Guayas

Se ubica en la quinta franja y ocupa la parte baja de los cuadros 22, 23 y 24. Su proa o punta delantera se dirige hacia la derecha.
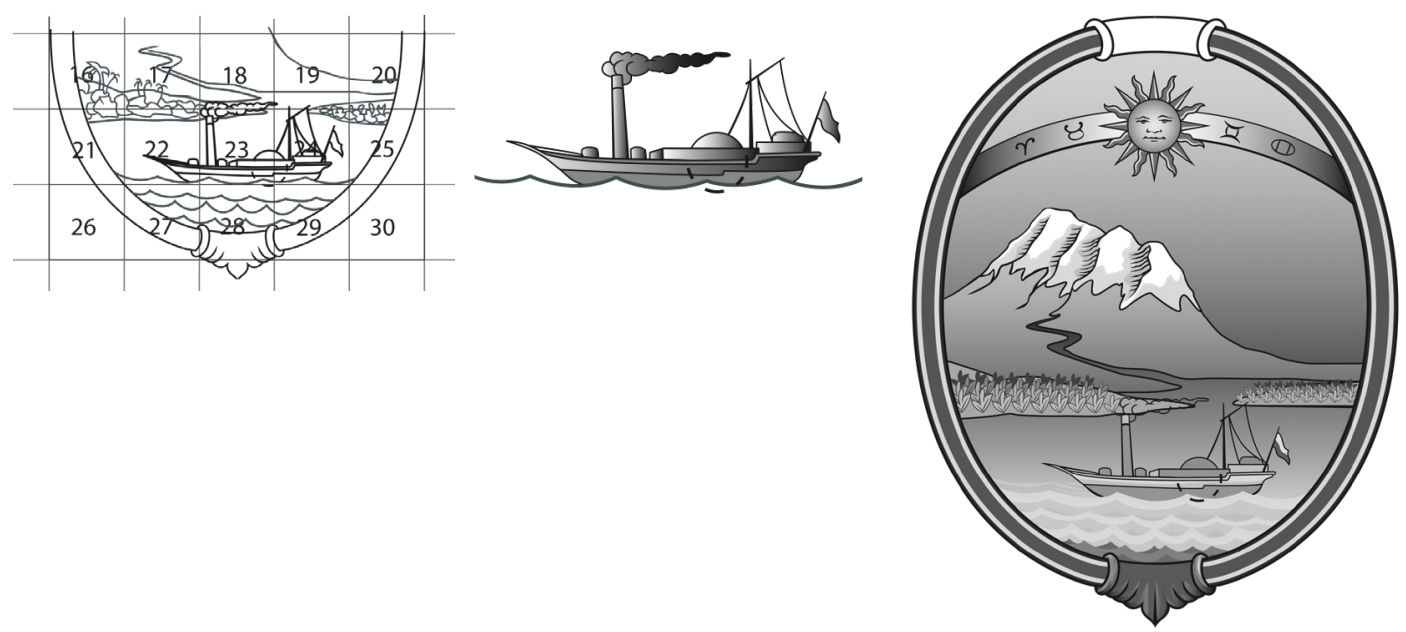


\section{El caduceo}

Vara delgada, lisa y cilíndrica rodeada de dos culebras y dos alas. A la manera de un mástil, se halla en el eje central del escudo y ocupa los cuadros n. ${ }^{\circ} 18$ y 23.
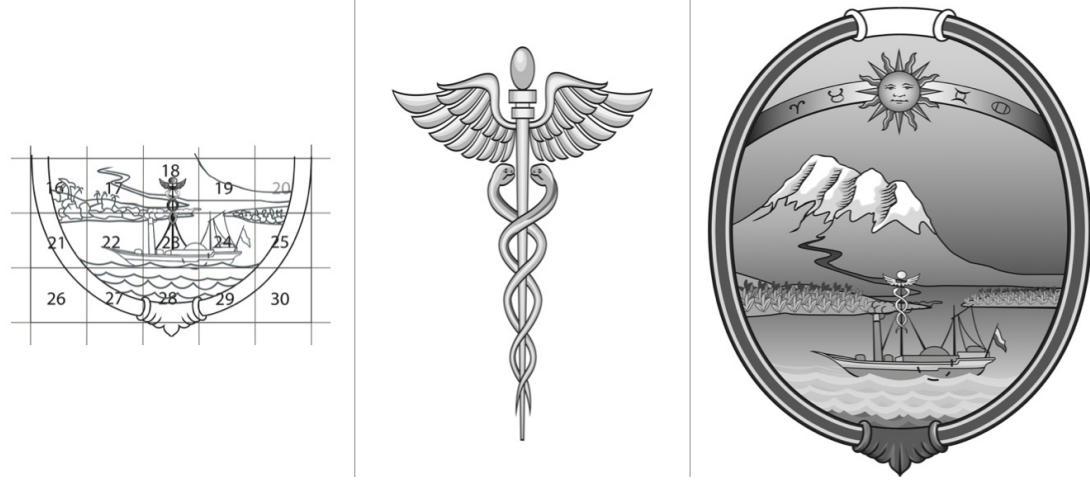

\subsection{Ornamentos externos}

Para su graficación, será necesario ampliar el rectángulo base dos filas más, a los cuatro costados. De esta forma, la nueva numeración de los recuadros del rectángulo ampliado queda de la siguiente manera:

\begin{tabular}{|c|c|c|c|c|c|c|c|c|}
\hline 1 & 2 & 3 & 4 & 5 & 6 & 7 & 8 & 9 \\
\hline 10 & 11 & 12 & 13 & 14 & 15 & 16 & 17 & 18 \\
\hline 19 & 20 & 21 & 22 & 23 & 24 & 25 & 26 & 27 \\
\hline 28 & 29 & 30 & 31 & 32 & 33 & 34 & 35 & 36 \\
\hline 37 & 38 & 39 & 40 & 41 & 42 & 43 & 44 & 45 \\
\hline 46 & 47 & 48 & 49 & 50 & 51 & 52 & 53 & 54 \\
\hline 55 & 56 & 57 & 58 & 59 & 60 & 61 & 62 & 63 \\
\hline 64 & 65 & 66 & 67 & 68 & 69 & 70 & 71 & 72 \\
\hline 73 & 74 & 75 & 76 & 77 & 78 & 79 & 80 & 81 \\
\hline 82 & 83 & 84 & 85 & 86 & 87 & 88 & 89 & 90 \\
\hline
\end{tabular}




\section{Cóndor ${ }^{2}$}

Su cuerpo ocupa los recuadros de la primera y segunda filas. Sin embargo, por su envergadura, supera, por arriba, en un $50 \%$ los recuadros 2,3 y 4 , así como los cuadros $6,7,8$ y 9.
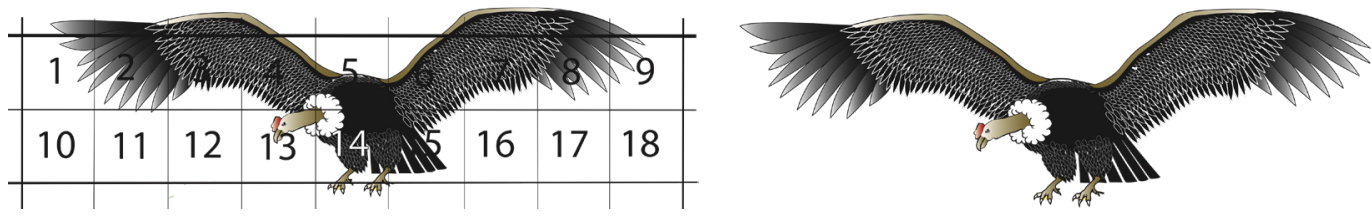

Astas posteriores (superiores)

Las dos astas de las banderas posteriores y superiores son lanzas que están inclinadas $40^{\circ}$ respecto de la horizontal. En el parte superior, disponen de puntas metálicas romboidales antecedidas por una media luna con su concavidad superior. En la derecha, se sitúa en la esquina inferior externa del cuadro n. ${ }^{\circ} 11$ y, en la izquierda, en el n. ${ }^{\circ} 17$. En el extremo inferior, aparecen con una punta terminal. En la derecha, corresponde a la porción superior externa del cuadro $n .^{\circ} 73 \mathrm{y}$, en la izquierda, al n. ${ }^{\circ} 81$. Tiene, en conjunto, una longitud de 10,5 medidas de largo. El punto de cruce se sitúa en el recuadro n. ${ }^{\circ} 41$.
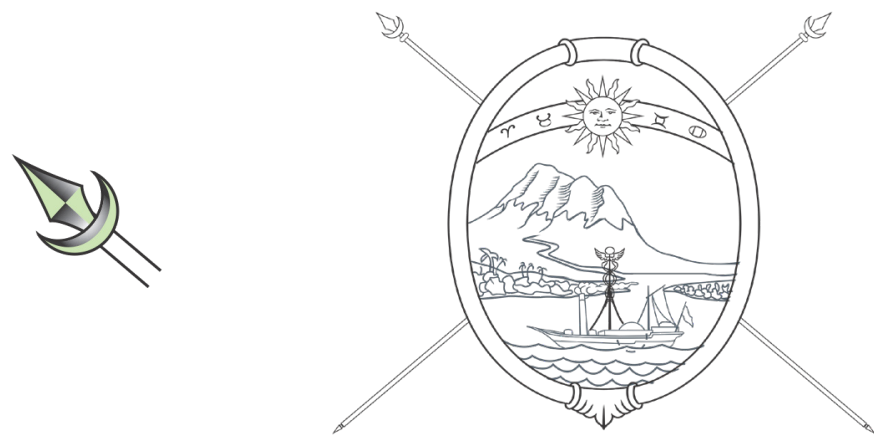

${ }^{2}$ Ninguno de los pintores que participaron en el concurso a inicios del siglo XX (ni el mismo Traversari) lograron plasmar gráficamente al cóndor anatómicamente y en el instante de levantar vuelo. Así, las alas son las partes en las que más incurren en error, pues ninguna se asemeja a su anatomía real. Esta circunstancia es la única en la que esta investigación no acepta y se desmarca del modelo Traversari y propone uno nuevo. 


\begin{tabular}{|c|c|c|c|c|c|c|c|c|}
\hline 1 & 2 & 3 & 4 & 5 & 6 & 7 & 8 & 9 \\
\hline 10 & y) 11 & 12 & 13 & 14 & 15 & 16 & 17 & 18 \\
\hline 19 & 20 & & & & & & 26 & 27 \\
\hline 28 & 29 & & & & & & 35 & 36 \\
\hline 37 & 38 & & & & & 43 & 44 & 45 \\
\hline 46 & 47 & & & & & & 53 & 54 \\
\hline 55 & 56 & & & & & & 62 & 63 \\
\hline & & & & & & & & \\
\hline 73 & 74 & 75 & 76 & 77 & 78 & 79 & 80 & 81 \\
\hline 82 & 83 & 84 & 85 & 86 & 87 & 88 & 89 & 90 \\
\hline
\end{tabular}

\section{Astas anteriores (inferiores)}

Las dos astas de las banderas anteriores e inferiores son lanzas que están inclinadas $40^{\circ}$ respecto de la horizontal. En el parte superior, disponen de puntas metálicas romboidales antecedidas por un hacha dirigida hacia abajo. En la derecha, corresponde a la porción inferior externa del recuadro n. ${ }^{\circ} 19 \mathrm{y}$, en la izquierda, al n. ${ }^{\circ} 27$. En el extremo inferior, aparece una punta terminal. En la derecha, aparece en la porción superior externa del cuadro n. ${ }^{\circ} 83 \mathrm{y}$, en la izquierda, en el n. ${ }^{\circ} 89$. Tiene, en conjunto, una longitud de 10,5 medidas de largo. El punto de cruce se sitúa en el recuadro n. ${ }^{\circ} 59$.

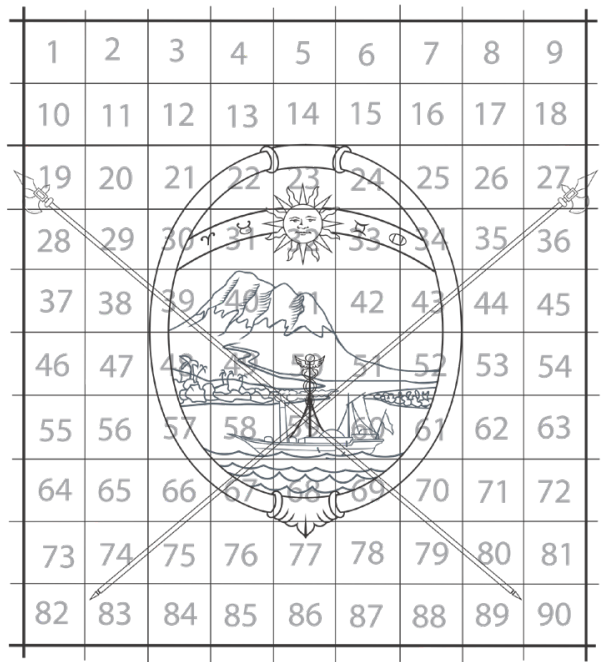

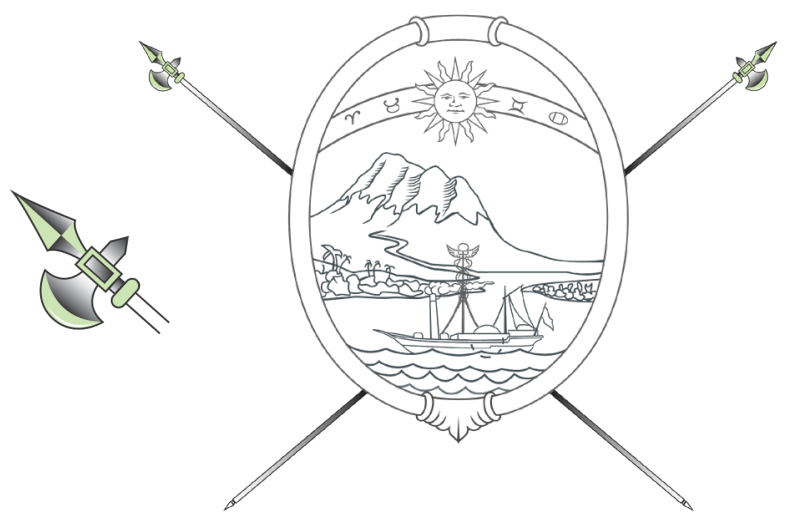

(C) UNED. Revista Signa 28 (2019), págs. 1413-1451 


\section{Banderas}

Las cuatro banderas, dos a cada lado, penden de sus respectivas astas inclinadas. En el costado derecho, las posteriores ocupan los cuadros n. $^{\circ}$ 20,29 y algo de los n. ${ }^{\circ} 21$ y 30 . Las banderas anteriores se ubican en los cuadros n. ${ }^{\circ} 38,47,56,65,74,66,74$ y 75 y en una parte de las casillas n. ${ }^{\circ}$ $28,37,46,55,64$. Ocurre de igual forma con las banderas correspondientes al costado izquierdo. Los extremos de dichas banderas bajan por detrás del haz de fasces consulares y ocupan los cuadros $n^{\circ}{ }^{\circ} 85,86$ y 87 y algo de los recuadros $n .^{\circ} 84$ y 88 .
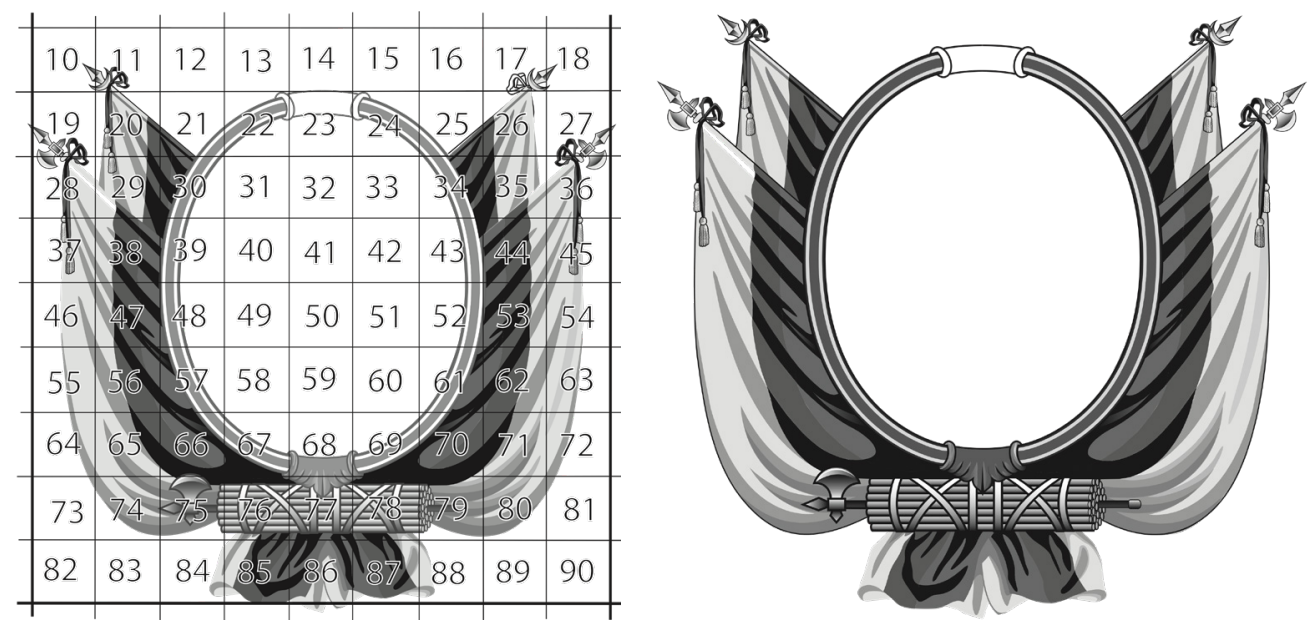

\section{Listones}

Los pabellones poseen sus respectivos listones en color azul y rojo, ajustados en lazo y adornados con una borla dorada en el extremo inferior. Atan las banderas en la parte más cercana a las puntas de cada lanza. En el lado derecho, los listones superiores ocupan los recuadros n. $.^{\circ} 11,20$ y 29 y los inferiores se sitúan en los cuadros n. ${ }^{\circ} 19,28$ y 37 . En el lado izquierdo, los listones superiores ocupan los recuadros n. ${ }^{\circ} 17,26$ y 35 y los inferiores, las casillas n. ${ }^{\circ} 27,35$ y 45.
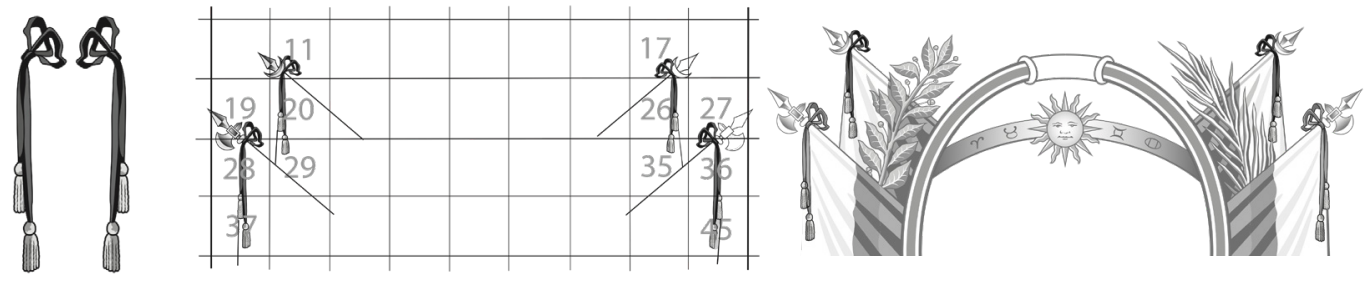


\section{Laurel}

Se ubica en el costado derecho, entre las banderas posterior-superior y anterior-inferior. Ocupa los recuadros n. ${ }^{\circ} 12,20,21,29,30$ y algo del cuadro n. ${ }^{\circ} 38$.
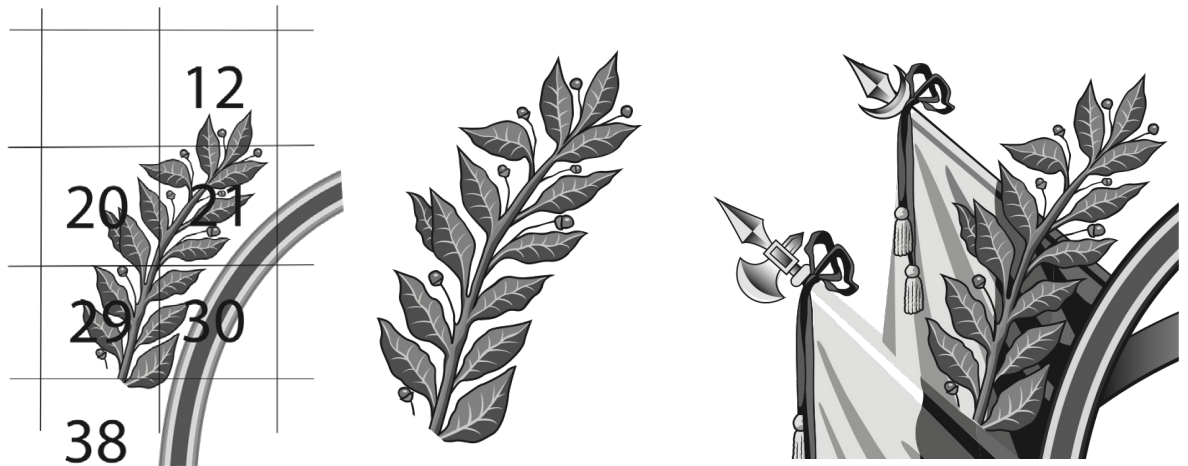

Palma

Está ubicada en el costado izquierdo, entre las banderas posterior-superior y anterior-inferior. Ocupa los recuadros n. ${ }^{\circ} 16,17,25,26,34$ y 35.
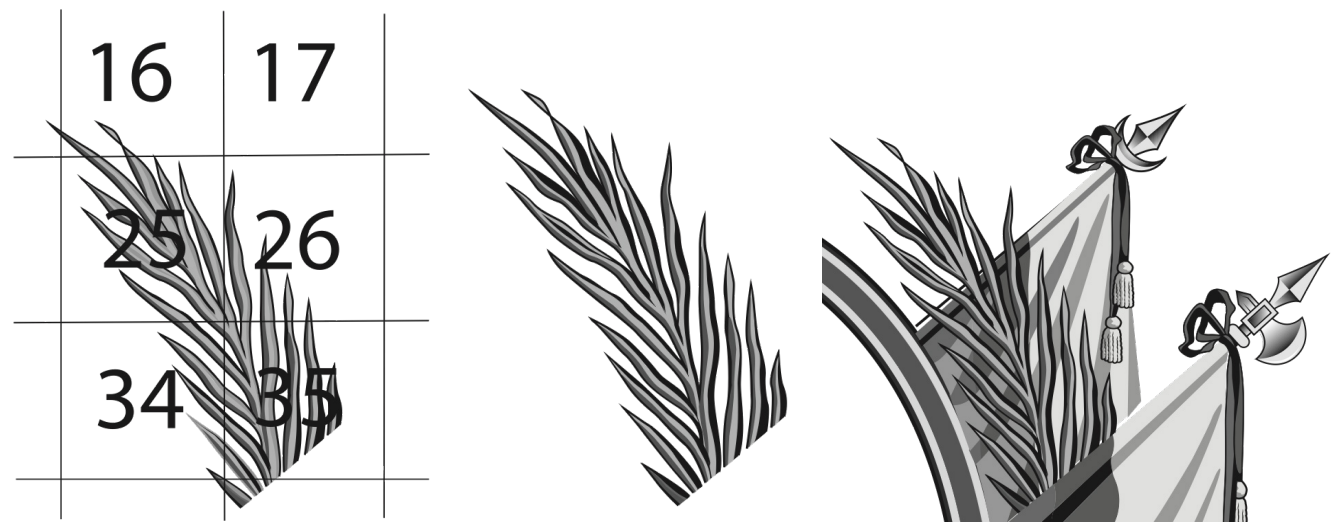


\section{Haz de fasces consulares}

El atado de varas ocupa los recuadros $n^{0}{ }^{0} 76,77$ y 78 . En cambio, la vara del hacha se ubica en el cuadro n. ${ }^{\circ} 79$ y su hoja, dirigida hacia arriba, en el n. ${ }^{\circ}$ 75. En definitiva, el conjunto de fasces consulares ocupa cinco recuadros, desde el n. ${ }^{\circ} 75$ hasta el n. ${ }^{\circ} 79$.

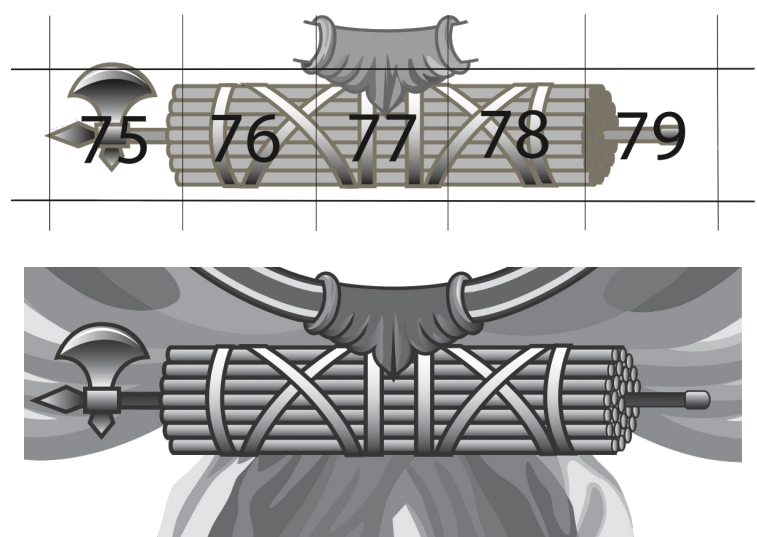

\subsection{Aspecto cromático}

Según el lenguaje heráldico, los conocidos esmaltes son de dos tipos: los metales, como el oro y la plata que están representados por el amarillo y el blanco; y los colores gules (rojo), azur (azul), sinople (verde), púrpura (morado) y sable (negro). Sin embargo, para su representación en monedas o en blasones esculpidos en piedra, hierro, bronce u otros objetos donde no se puede colorear, se utiliza el invento del sacerdote jesuita Silvestre Pietra $\operatorname{Santa}^{3}$ que utiliza líneas y puntos. Esta variable no se sujeta sino

\footnotetext{
${ }^{3} \mathrm{Al}$ oro se lo muestra con puntos; al color plata se lo representa sin señal alguna; los gules, con líneas verticales; y los azures, con horizontales. El sinople se detalla con líneas diagonales que vienen del ángulo diestro del jefe del escudo al siniestro bajo de la punta y el púrpura se señala con líneas que bajan del ángulo siniestro de lo alto del jefe al
} 
a uno que otro elemento del escudo que debería tener colores definidos, según las normas colorimétricas de uso universal como, por ejemplo, el PANTONE PMS (Pantone Matching System). De ahí la dificultad de concebir al escudo ecuatoriano dentro de esta normativa heráldica, sin embargo, en el caso de las banderas es mandatorio que se ajusten a un número de Pantone universal y, con ello, terminar definitivamente con las presentaciones disímiles.

Los códigos numéricos asignados para los tres colores son:

\begin{tabular}{|c|c|c|c|}
\hline Denominación & Amarillo & Azul & Rojo \\
\hline PANTONE & 116 & 287 & 186 \\
\hline
\end{tabular}

Los degradados en el color que se ponen en el escudo se justifican en la medida que representan directamente sus elementos y, por ello, el uso justificado de luces y sombras. Habrá que aceptar que los colores cumplieron también roles protagónicos en las obras de arte o de diseño puesto que llegaron tener distinta representación dependiendo la época de utilización.

\subsection{Como "un todo"}

El campo ovalado y sus ornamentos externos son complementarios y para entender sus dibujos configurantes con sus significados se ha recurrido al método iconográfico de Panofsky para la descripción y análisis de cada uno y, solo después, para entenderlo como una unidad estructural y con un solo sentido.

diestro bajo de la punta. Finalmente, el sable se representa con un entramado de líneas horizontales y verticales (García Carraffa, 1919: 34). 
Aunque el método iconográfico ${ }^{4}$ ya fue utilizado desde el siglo XVI, será en el XVIII que se desarrolló ampliamente gracias al estudio del patrimonio figurativo del origen sacro. Walburg, por ejemplo, creía que a través del arte se podía indagar el talante sicológico y la mentalidad de una época. El gran aporte de Panofsky se centra en haber patentado un tridente metodológico de estudio que describe primero el objeto de estudio, luego —en el análisis iconográfico - descubre los significados en cada uno de los elementos de la obra y, en el —iconológico — pone en relación el tema representado con su significado profundo y lo analiza en el contexto cultural de su tiempo.

Por otro lado, las imágenes son eminentemente mudas, pero dicen mucho. Burke (2015: 11) y son, precisamente esas evocaciones del pasado las que pueden ser utilizadas como documento histórico. Los escudos, por todo ello, son importantes en el entramado social en la medida que guardan, dentro de su gráfica visual, un mundo de acontecimintos. Y esa importancia simbólica es la que se debe precautelar a traves de modelos estandarizados que perduren en el tiempo.

\subsubsection{El escudo}

\section{Descripción pre-iconográfica}

En la parte superior del campo, aparece una cinta ovalada de concavidad inferior, en medio de la cual se encuentra un sol flameado y enmascarado. En la parte derecha, se ubican dos signos zodiacales y, a la izquierda, otros dos más. Debajo de este conjunto, en el costado derecho, aparece un volcán nevado del cual nace un río que baja y se ensancha en

\footnotetext{
${ }^{4}$ La iconografía se ocupa de la interpretación de las imágenes representadas en las obras de arte.
} 
la parte inferior del campo. En sus riberas, aparece mucha vegetación y, en sus aguas, un barco a vapor que navega hacia la derecha. Tiene por mástil un madero rodeado de dos culebras y, en su parte superior, dos alas desplegadas.

\section{Análisis iconográfico}

La parte superior del campo está fondeado de azul celeste - a semejanza del cielo - en que aparece un sol dorado (oro), connotación que tiene que ver con la riqueza material y cultural de los pueblos prehispánicos, pero también es flameado y enmascarado, ya que representa al dios andino. Este sol se halla en medio de una faja de curvatura inferior, que va de un costado al otro, denominada eclíptica, ecuatorial y/o equinoccial, representa la porción de cielo que cubre al Ecuador y tiene que ver con la centralidad planetaria en la que se encuentra el país. A la derecha, se hallan los signos zodiacales de Aries y Tauro y, a la izquierda, Géminis y Cáncer que representan a marzo, abril, mayo y junio, los meses en que se produjeron los hechos más importantes de la Revolución marcista del año 1845, con la que se terminó la hegemonía política del presidente Juan José Flores y se inauguraron los gobiernos “civilistas". Todo este conjunto simbólico encarna el nominativo de Ecuador, nombre con el que se bautizó al país en la Carta Constitucional de 1830.

El volcán de la parte central derecha del campo es el Chimborazo y representa a la Sierra, una de las dos grandes regiones que forman parte del Ecuador. De sus nieves nace un río que baja por sus faldas y termina ensanchándose en un mar, en la parte inferior del campo. El río Guayas es el accidente geográfico que une la Sierra con la Costa y, con ello, se formula el concepto de UNIDAD NACIONAL, concebido por la Revolución marcista. La cuenca del río Guayas, única por su riqueza natural y productiva, está representada en la abundante vegetación que se dibuja a sus orillas. De la 
misma manera, en las aguas del océano Pacífico, navega un barco a vapor, concebido y construido en los astilleros guayaquileños a mediados del XIX. Este hecho induce a pensar, por un lado, en la capacidad inventiva de los ecuatorianos y, por otro, en el comercio exterior del cacao a nivel internacional. Para corroborar este aserto, aparece como mástil un caduceo, símbolo del comercio.

\section{Análisis iconológico}

La centralidad de la que goza el país se refleja en la posición que ocupan el sol y la eclíptica conjuntados en lo más alto y céntrico del escudo como el amplio paraguas celeste que cubre al resto de elementos. Este logro gráfico debió constituirse en un elemento de difícil consecución, debido a que representa a un elemento imaginario/etéreo como es el ecuador, es decir, a la simple línea imaginaria concebida por los geodésicos franceses a mediados del XVIII que circunda el planeta y que lo divide en dos hemisferios. Su materialización constituyó un significativo logro que hubo de pervivir incólume, salvo algunos pequeños añadidos posteriores, a lo largo de todo su proceso configurativo.

Ningún diseño posterior alteró su forma porque desde el inicio se constituyó en el ícono representativo de la nación. Hubo cambios de la forma e incluso de los elementos de su campo, según los diversos mensajes que se quiso transmitir, pero en ningún caso el nominativo que, a manera de título, siempre acompañó a los diferentes modelos que posteriormente se implantaron en la parte media y baja del escudo.

Los fundamentos conceptuales/políticos que movilizóla Revolución marcista de 1845 tuvo que ver con el logro de la tan anhelada unidad, pues las dos grandes regiones del país vivían importantes divergencias económicas, sociales y políticas. De esta forma, por primera vez, se graficaba a la Costa en el símbolo. 
Esta unidad fue graficada con el volcán Chimborazo, en planos más profundos y el nacimiento de un río que naciendo en la Sierra, fluye, se acerca y se expande por la Costa, en primeros planos, que comparte con la porción del mar océano en cuyas aguas aparece un barco a vapor con dirección a la diestra. Esta evolución gráfica permitió hacer una lectura desde la Costa hacia la Sierra, es decir, de fuera hacia dentro, a la manera de una ventana abierta. Se graficaba así el concepto del Ecuador unido que ya más nunca se modificó como concepto gráfico. Por tanto, en concepto final, alude al Ecuador unido y progresista-exportador.

La organización en que se presentan los distintos elementos define un mensaje conjunto que busca materializar el mito fundacional de creación de la nación. "si los mitos tienen un sentido, éste no puede depender de los elementos aislados que entran en su composición, sino de la manera en que estos elementos se encuentran combinados" Gomez (1981:131). En definitiva, el mito contemporiza los acontecimientos de los tiempos pasados y los escudos, en cuanto organiza los distintos elementos visuales, ponen en el día a día y en la mente de los ciudadanos, la idea de un tiempo original.

\subsubsection{Ornamentos externos}

\section{Descripción preiconográfica}

Por fuera del escudo, aparece, en la parte superior, un cóndor en procura de levantar vuelo. A los costados, de cuatro astas inclinadas, penden igual número de banderas tricolores que se recogen en la parte baja y posterior del óvalo, el cual descansa en un atado de fasces (palitos) consulares atados con cuerdas rojas presentadas de forma horizontal y una hacha cruzada de izquierda a derecha con su hoja dirigida hacia arriba. Por debajo de este haz, aparecen los bordes de las banderas. Entre las banderas 
del costado derecho emerge una rama de laurel y, en la izquierda, una de palma.

\section{Análisis iconográfico}

El cóndor, el ave voladora más grande de América, da cuenta de la voluntad y carácter de la gente ecuatoriana, siempre en actitud de elevar vuelo hacia la conquista de altos objetivos.

Las cuatro banderas penden de igual número de astas, sin embargo, las superiores-posteriores son astas sencillas con una media luna abierta hacia fuera y su punta correspondiente. Las dos inferiores-anteriores tienen también una hoja de hacha dirigida hacia abajo, conocida como punta de alabarda. Las cuatro banderas presentan por fuera, el color amarillo con un 50\% del ancho; el azul, un $25 \%$ al centro; y el rojo, el restante $25 \%$ por dentro. Simbolizan a las milicias locales y a sus campañas liberadoras. Adviértase aquí el carácter militarista de la unión entre las astas y sus banderas. El conjunto superior representa a las tropas americanas y las inferiores, a las milicias españolas.

En la parte baja, un atado de palitos en forma tranversal y atravezado por una hacha. Este conjunto representa a los líctores romanos que legislaban a favor de la república y es elemento donde descansa el escudo.

Análisis iconológico

El simbolismo que encarna la presencia del cóndor en la corona tiene que ver con el carácter de la gente ecuatoriana. Su fortaleza, fidelidad, 
templanza, dignidad y nobleza han sido atribuidas a una población que, a lo largo de la historia, ha sabido sortear con éxito las dificultades impuestas. La analogía de un cóndor en actitud de levantar vuelo supone la postura emprendedora de los individuos que buscan elevarse llevando consigo al escudo, es decir, a la nación entera, en atención a que históricamente las comunidades prehispánicas consideraron a esta ave como un ser poderoso capaz de sacar de las tinieblas al Sol para luego elevarlo a lo alto del medio día.

El simbolismo que se adjudica al conjunto de banderas, con sus astas, tiene que ver con las fuerzas militares que lograron el rompimiento del orden colonial en el siglo XIX. ¿Qué hacen, entonces, las astas inferiores con punta de alabarda que representan a las fuerzas hispanas? ¿Acaso se las incluyó como una forma de mostrar las buenas relaciones que ya se habían establecido con la madre patria?

De cualquier forma, se ha dado por hecho que la institución armada es la llamada a proteger y a respaldar a la República, tanto en tiempos de paz como en los de guerra. Las banderas literalmente abrazan al escudo.

Por su parte, el atado de fasces deviene un símbolo de los legisladores romanos y establece una relación con el orden republicano. Estos constituyen el soporte en el que descansa la nación. La unión de varas hace más difícil romperlas; ahí radica el poder. Por otra parte, el hacha que las cruza representa la justicia implacable que está sobre la vida y la muerte. Conjunción de elementos que determinan que la nación descansa en el respeto de los tres poderes del Estado.

Entre las banderas laterales izquierdas y derechas, una anterior y otra posterior, aparece una rama de laurel al lado derecho y una de palma al izquierdo. Su presencia conlleva una significación religiosa, pues la paz y la gloria son enunciados impuestos por la Iglesia. De suyo, el catolicismo decretado como religión oficial del Estado desde los inicios republicanos también está presente en la medida que la corporación eclesiástica también reivindicó su presencia como forjadora de la nacionalidad ecuatoriana. De 
esta forma, el militarismo y el catolicismo se conciben como protectores de la nación.

De esta forma se obtiene un concepto global: El Ecuador unido y progresista, liderado por un pueblo altivo que descansa en el orden republicano y protegido por los ámbitos militar y religioso.

\section{DISCUSIÓN}

La aplicación del método DAERDI se inscribe como una opción que facilita una mejor comprensión conceptual de este tipo de escudos en la medida que su desarrollo, por partes y de forma ordenada evita, o al menos disminuye, el cometimiento de errores. Por esta razón, se lo propone además como una fórmula que permitirá a todos quienes quieran graficar este tipo de emblemas regirse bajo los parámetros normados a fin de obtener un escudo estandarizado en proporciones, dimensiones y colorimetría, es decir, definido en su correcta reproducción con fines especialmente oficiales, dado el carácter simbólico que encarna.

Hay que señalar también que el método propuesto no excluye el desarrollo y aplicación de otros en atención a las diversas necesidades que se presenten, así como la voluntad expresa de los investigadores por trastocar el orden aquí establecido. Esta tarea se la puede hacer también mediante el uso de programas de computación, siempre y cuando se ciñan a las normativas señaladas. En definitiva, el sistema propuesto está diseñado para ser utilizado en cualquier tipo de escudos de representación directa y de la forma en la que el investigador/diseñador lo crea conveniente.

En Ecuador, sin embargo, se hace imperativo utilizar un método ante la necesidad de estandarizar un solo modelo gráfico y de esta manera, mantener incólume su valor simbólico. En términos generales, los ciudadanos ecuatorianos reconocen los elementos que conforman el escudo, pero no todos identifican los significados que encarnan y peor aún, 
pueden hacer una lectura del cúmulo de elementos conjugados en uno solo. Símbolo que, sin duda, habla de un mundo natural y también sobrenatural, pues en él se encarnan incluso mitos fundadores de la república.

\section{CONCLUSIONES}

Para objeto de este estudio, al escudo del Ecuador se lo denominó de representación directa porque en su configuración se hallan representados algunos elementos del entorno natural. Por otra parte, tanto sus formas como sus colores se alejan de los códigos heráldicos. Debido a estas consideraciones, más por tradición que por otra circunstancia, se lo puede seguir llamando de armas sin que por ello pierda o gane valor.

Por otro lado, el actual escudo desde que fue concebido ha vivido una suerte de desconocimiento por parte de la ciudadanía. Esto tiene que ver con dos circunstancias claramente identificadas: la primera, con los escasos esfuerzos gubernamentales por su enseñanza cabal en el territorio a través del sistema educativo y, la segunda, con la carencia de un solo modelo gráfico que se haya insertado en el imaginario colectivo. La multiplicidad de modelos que a lo largo de los siglos XIX y XX han circulado en el país ha conspirado con su adecuada comprensión y haya propiciado más la desorientación y la anarquía. Por otro lado, no hay explicación alguna por la que se haya desconocido e ignorado el modelo de Pedro Pablo Traversari quien, a inicios del siglo XX, fuera el triunfador del concurso convocado por el presidente Eloy Alfaro y ratificado como oficial de la República por el Ministerio de Instrucción Pública en el año 1916.

El reto de los últimos años se ha centrado en encontrar un solo modelo gráfico. Estandarización que parecía haberse logrado en el año 2003, gracias a que la Cancillería de la nación propuso al Congreso, aunque este no tenía nada que ver con el de Traversari. Pese a que la legislatura lo aprobó mediante Resolución n. ${ }^{\circ}$ R-24-047 de 25 de febrero, el problema 
subsiste. Frente a esta circunstancia, la necesidad de utilizar un método que permita graficar un solo modelo que homogenice un mismo diseño gráfico en atención a las normas heráldicas adaptadas para un escudo de representación directa.

En la actualidad, más se diseñan marcas que identifican a grupos $\mathrm{u}$ organizaciones. $\mathrm{Y}$ aunque responden a similares necesidades de comunicación visual, el simbolismo que encarnan los escudos es preponderante en la medida que han fijado en la mente de los ciudadanos unos imaginarios nacionalistas. Sin embargo, para que mantenga su vigencia es necesario que los individuos reconozcan sus significaciones. Para que aquello ocurra, además del proceso de socialización, será requisito que su arraigo en el imaginario colectivo dependa de su mantenimiento en el tiempo, pues cuan más viejos, mejor. De igual forma, cuanto más fáciles de reproducir, su carácter simbólico y su penetración social serán más importantes y se mantendrán en el tiempo.

A lo largo de estas líneas, se ha procurado orientar una metodología y algunos mecanismos adecuados para una reproducción gráfica, pero con conocimiento de causa, reconociendo parte por parte sus contenidos y su valor simbólico, sus proporciones y su adecuada ubicación dentro o fuera de él. Que la noción de unión nacional, como el principal concepto que le fue asignado desde sus inicios, debe ser socializado a la par de su adecuada reproducción gráfica. Este debe ser el argumento de su continuidad en el tiempo a la par que los ciudadanos lo reconozcan como su símbolo identificatorio. 


\section{REFERENCIAS BIBLIOGRÁFICAS}

BAÑUELOS, J. (2006). "Aplicación de la semiótica a los procesos del diseño". Signa. Revista de la Asociación Española de Semiótica 15, 233-254.

BARTHES, R. (1994). El susurro del lenguaje, más allá de la palabra y de la escritura. Barcelona: Paidós.

BURKE, P. (2005). Visto y no visto, el uso de la imagen como documento histórico. Barcelona: A\&M Grafic.

DE LA CERDA Y PITA, M. (1990). Heráldica española: el diseño heráldico. Madrid: Grupo Centro.

ECO, U. (1988). Signo. Traducción de Francisco Serra Cantarell. Barcelona: Labor.

(1995). Semiótica y filosofía del lenguaje. Barcelona: Lumen.

GARCÍA, X. (2011). Dibujo heráldico. Pasos a seguir para dibujar un escudo. http://dibujoheraldico.blogspot.com/2011/06/pasosseguir-para-dibujar-un-escudo.html [15-11-2017].

GARCÍA CARRAFFA, A. (1919). Enciclopedia heráldica y genealógica hispano-americana. Ciencia heráldica o del blasón (t. I). Madrid: Imprenta de Antonio Marzo.

GÓMEZ GARCÍA, P. (1981). La antropología estructural de Claude LeviStrauss, ciencia, filosofía, ideología. Madrid: Tecnos.

GREIMAS, J. (1973). En torno al sentido: ensayos semióticos. Madrid: Fragua.

LÉVI-STRAUSS, L. (1995). Antropología estructural. Barcelona: Paidós.

SOSA, R. (2014). El escudo de armas del Ecuador y el proyecto nacional. Quito: Universidad Andina Simón Bolívar-Corporación Editora Nacional. 
WALBURG, A. (2005). El renacimiento del paganismo. Madrid: Alianza.

WILliAMS, R. (1992). Historia de la comunicación, del lenguaje a la escritura. Barcelona: Tesys.

Recibido el 4 de febrero de 2018.

Aceptado el 30 de mayo de 2018. 
